\title{
Photovoltaic system derived data for determining the solar resource and for modeling the performance of other photovoltaic systems
}

\author{
Bill Marion ${ }^{\mathrm{a}, *}$, Benjamin Smith ${ }^{\mathrm{b}}$
}

\begin{abstract}
Using performance data from some of the millions of installed photovoltaic (PV) modules with micro-inverters may afford the opportunity to provide ground-based solar resource data critical for developing PV projects. A method was developed to backsolve for the direct normal irradiance (DNI) and the diffuse horizontal irradiance (DHI) from the measured ac power of southfacing PV module/micro-inverter systems. The method was validated using one year of irradiance and PV performance measurements for five PV systems, each with a different tilt/azimuth orientation, and located in Golden, Colorado. Compared to using a measured global horizontal irradiance for PV performance model input, using the back-solved values of DNI and DHI only increased the range of mean bias deviations from measured values by $0.6 \%$ for the modeled annual averages of the global tilt irradiance and ac power for the five PV systems. Correcting for angle-of-incidence effects is an important feature of the method to prevent underestimating the solar resource and for modeling the performance of PV systems with more dissimilar PV module orientations. The results for the method were also shown more favorable than the results when using an existing power projection method for estimating the ac power.
\end{abstract}

Key words: Direct normal irradiance; Diffuse horizontal irradiance; Photovoltaic system performance; Model.

\section{Introduction}

Ground-based solar resource measurements are critical for developing photovoltaic (PV) projects. Unfortunately, accurate measurements at most locations are lacking due to the cost of solar radiation measurement equipment, which can be more than $\$ 40,000$ for a first class station. To provide low or no-cost solar resource data traceable to a ground-based physical measurement at a nearby location, we have been developing a method to derive solar resource data from PV performance data such as measured by Enphase Energy Inc. micro-inverters, which have been deployed with millions of PV modules and have been providing reliable data with a 5-minute temporal resolution since 2011 - and for some early systems since 2007.

This work uses PV performance data to back-solve for the unknown direct normal irradiance (DNI) and diffuse horizontal irradiance (DHI). It required the development of two key methods: 1) determining the global tilted irradiance (GTI), otherwise known as the plane-of-array (POA) irradiance, from the ac power $\left(P_{a c}\right)$, and 2) determining the DNI and DHI from the GTI. The DNI and DHI values, or their global horizontal irradiance (GHI) equivalent, may then be used with conventional modeling software, such as PVsyst, Helioscope, and the National Renewable Energy Laboratory's (NREL's) System Advisor Model (SAM), to estimate the performance of PV systems of any size, or PV array tilt and azimuth orientation, including tracking.

We recently published a method to determine the DNI and DHI from the GTI when measured with pyranometers (Marion, 2015). It is a modification of the DIRINT model by Perez et al. (1992), which separates input values of GHI into their DNI and DHI components. The modification substitutes GTI for GHI, and adds an iterative procedure to adjust the global clearness index to improve the derived values of DNI and DHI. The resulting model is referred to as the GTI-DIRINT model. The GTI-DIRINT model was validated using GTI values measured with Kipp \& Zonen CMP11 and CMP22 pyranometers for three climatically diverse locations: Cocoa, Florida; Eugene, Oregon; and Golden, Colorado. For the GTI measured at a small tilt angle from the horizontal $\left(10^{\circ}\right)$ and south-facing, the deviations between the measured DNI and DHI and the GTI-DIRINT modeled DNI and DHI were essentially the same as those for the DIRINT model when using the GHI for model input. For larger tilt angles from horizontal, the deviations between modeled and measured values were larger, but still reasonable. Results were least favorable for GTIs measured with a pyranometer tilt angle from horizontal of $40^{\circ}$ and an azimuth angle from north of $210^{\circ}$, with deviations between modeled and measured values of DNI almost twice as great as for the south-facing GTIs.

More recently, Gostein et al. (2016) successfully applied the GTI-DIRINT model for use with one-axis tracking PV modules with the axis horizontal and oriented north-south. This orientation results in the PV module being tilted at small angles during 
midday, a favorable condition because the GTI-DIRINT model is functionally the same as the DIRINT model if the tilt is horizontal and the GTI equals the GHI.

This work developed and validated a method to derive the GTI from the $P_{a c}$ for south-facing PV modules, the optimal orientation based on our previous work, and then to use the GTI-DIRINT model to determine the DNI and DHI. Results are presented for implementing the overall procedure to derive the DNI and DHI from the $P_{a c}$, and for then using the derived values of DNI and DHI to model the GTI and $P_{a c}$ for various tilted orientations, including non-south-facing and tracking.

Recent work of a related nature includes that of da Costa et al. (2014), where irradiance and temperature are both derived from operating points on the PV module current-voltage curve, but at the expense of interrupting the operation the PV module at its maximum power. The GTI-DIRINT model uses a method similar to that of Yang et al. (2013) and Yang et al. (2014), but the iteration procedure uses the anisotropic transposition model of Perez et al. (1990) in place of an isotropic transposition model.

Killinger et al. (2016) provides a power projection method for estimating the performance of one PV system from that of another, which is quite similar to our method. They use the GTI-DIRINT model for one of their variants, and we have adopted their technique of using a quadratic solution to determine the GTI from the $P_{a c}$, but have added provisions to account for the effect of wind speed on PV module temperature, inverter efficiency as a function of load, and increased reflection losses due to the angle-of-incidence (AOI) of direct and diffuse solar radiation.

Another power projection method uses a "clear sky index for PV" (Engerer and Mills, 2014). The index is determined by dividing the measured PV power by that calculated for clear-sky conditions. To estimate the performance of a nearby PV system, the PV power calculated for the nearby PV system for clear-sky conditions is multiplied by the index. Lonij et al. (2011) uses a similar index to forecast the power output of PV systems. For best results when using these types of indices, the orientation of the PV systems should be similar because the contributions of the direct and diffuse solar radiation are not treated separately. To address this concern, Engerer and $\mathrm{Xu}$ (2015) later developed a method to estimate the diffuse fraction from the "clear sky index for PV."

The following sections discuss the method for determining the DNI and DHI from the $P_{a c}$, data used for validating the method, implementation of the method, results and their analysis, summary and conclusions from the key outcomes, and future work.

\begin{tabular}{|c|c|c|c|}
\hline \multicolumn{4}{|c|}{ Nomenclature } \\
\hline$A, B, C$ & Quadratic equation constants & $P_{s o}$ & Self-consumption of inverter $(\mathrm{W})$ \\
\hline $\mathrm{AOI}$ & Angle-of-incidence $\left(^{\circ}\right)$ & $R$ & Range of $\omega$ \\
\hline$D$ & GTI subtracted from GTI $_{m}$ & RMSD & Root-mean-square deviation (\%) \\
\hline DHI & Diffuse horizontal irradiance $\left(\mathrm{W} / \mathrm{m}^{2}\right)$ & STC & Standard Test Conditions \\
\hline DNI & Direct normal irradiance $\left(\mathrm{W} / \mathrm{m}^{2}\right)$ & $T$ & PV cell temperature $\left({ }^{\circ} \mathrm{C}\right)$ \\
\hline$F$ & AOI correction factor for diffuse irradiance & $T_{0}$ & $T$ at $\mathrm{STC}, 25^{\circ} \mathrm{C}$ \\
\hline$F_{b}$ & $\begin{array}{l}\text { AOI correction factor for beam and } \\
\text { circumsolar irradiance }\end{array}$ & $T_{a}$ & Ambient dry bulb temperature $\left({ }^{\circ} \mathrm{C}\right)$ \\
\hline$F_{s k y}$ & $\begin{array}{l}\text { AOI correction factor for diffuse sky } \\
\text { irradiance }\end{array}$ & $\Delta T_{c}$ & $\begin{array}{l}\text { Difference between the cell temperature and the } \\
\text { back surface of the PV module when GTI equals } \\
\text { GTI }_{0}\left({ }^{\circ} \mathrm{C}\right)\end{array}$ \\
\hline$F_{\text {hor }}$ & $\begin{array}{l}\text { AOI correction factor for horizon diffuse } \\
\text { irradiance }\end{array}$ & $W S$ & Wind speed at a 10 meter height $(\mathrm{m} / \mathrm{s})$ \\
\hline$F_{\text {grd }}$ & $\begin{array}{l}\text { AOI correction factor for ground-reflected } \\
\text { diffuse irradiance }\end{array}$ & $a_{0}-a_{5}$ & $\begin{array}{l}\text { Polynomial coefficients for AOI correction } \\
\text { factors }\end{array}$ \\
\hline$F_{1}$ & $\begin{array}{l}\text { Perez model circumsolar anisotropy } \\
\text { coefficient }\end{array}$ & $a, b$ & $\begin{array}{l}\text { Empirical Sandia temperature coefficients } \\
\text { depending on the PV module construction and } \\
\text { mounting configuration }\end{array}$ \\
\hline$F_{2}$ & $\begin{array}{l}\text { Perez model horizon/zenith anisotropy } \\
\text { coefficient }\end{array}$ & $c_{0}-c_{6}$ & Coefficients for the Killinger method \\
\hline GHI & Global horizontal irradiance $\left(\mathrm{W} / \mathrm{m}^{2}\right)$ & $c$ & $\max (0$, cosine of AOI $)$ \\
\hline GTI & Global tilt irradiance $\left(\mathrm{W} / \mathrm{m}^{2}\right)$ & $d$ & $\max (0.087$, cosine of solar zenith angle $)$ \\
\hline $\mathrm{GTI}_{0}$ & GTI at STC, $1000 \mathrm{~W} / \mathrm{m}^{2}$ & $n$ & Refractive index \\
\hline $\mathrm{GTI}_{m}$ & $\begin{array}{l}\text { Modeled GTI corrected for AOI losses } \\
\left(\mathrm{W} / \mathrm{m}^{2}\right)\end{array}$ & $m$ & Number of measured or modeled values \\
\hline MBD & Mean bias deviation $(\%)$ & $x_{i}$ & The $i$ th measured value \\
\hline$P_{a c}$ & AC power $(\mathrm{W})$ & $y_{i}$ & The $i$ th modeled value \\
\hline$P_{\text {aco }}$ & $\mathrm{AC}$ power rating of inverter $(\mathrm{W})$ & $\beta$ & PV module tilt angle from the horizontal $\left({ }^{\circ}\right)$ \\
\hline$P_{a c 0}$ & $\mathrm{AC}$ power at STC $(\mathrm{W})$ & $\gamma$ & Power correction factor for temperature $\left({ }^{\circ} \mathrm{C}^{-1}\right)$ \\
\hline$P_{d c}$ & DC power $(\mathrm{W})$ & $\rho$ & Albedo of the ground \\
\hline
\end{tabular}




\section{Method description}

The following sections describe the method's two key elements: (1) deriving the GTI from the ac power, and (2) deriving the DNI and DHI from the GTI using the GTI-DIRINT model.

\subsection{Deriving the GTI from the ac power}

The solution for deriving the GTI from the ac power is a two-step process where the dc power $\left(P_{d c}\right)$ is first derived from the $P_{a c}$ and then the GTI is derived from the $P_{d c}$. This is opposite to the normal modeling chain of PV performance software; consequently, inverted PV performance equations are used based on conventional equations for $P_{a c}$ and $P_{d c}$ and PV cell temperature (T). Eq. (1) represents the equation for $P_{a c}$ from the Sandia inverter performance model when using the default values of zero for the Sandia empirical coefficients (King et al., 2007).

$$
P_{a c}=P_{a c o} \cdot\left(P_{d c}-P_{s o}\right) /\left(P_{d c o}-P_{s o}\right)
$$

where $P_{\text {aco }}$ is the inverter ac power rating, $\mathrm{W} ; P_{s o}$ is the self-consumption by the inverter, $\mathrm{W}$; and $P_{d c o}$ is the inverter dc power rating, $\mathrm{W}$.

Eq. (2) is the equation for $P_{d c}$ based on the original linear expression for PV efficiency by Evans and Florschuetz (1977):

$$
P_{d c}=P_{d c 0} \cdot\left[1+\gamma \cdot\left(T-T_{0}\right)\right] \cdot \mathrm{GTI} / \mathrm{GTI}_{0}
$$

where $\gamma$ is the power correction factor for temperature, ${ }^{\circ} \mathrm{C}^{-1}$; and the zero subscripts denote Standard Test Conditions (STC): $\mathrm{GTI}_{0}=1000 \mathrm{~W} / \mathrm{m}^{2}$ and $T_{0}=25^{\circ} \mathrm{C}$.

Eq. (3) is the equation for $T$, used for input for Eq. (2), from the Sandia PV array performance model (King et al., 2004):

$$
T=T_{a}+\Delta T_{c} \cdot \mathrm{GTI} / \mathrm{GTI}_{0}+\mathrm{GTI} \cdot e^{a+b \cdot W S},
$$

where $T_{a}$ is the ambient dry bulb temperature, ${ }^{\circ} \mathrm{C} ; \Delta T_{c}$ is the difference between the cell temperature and the back surface of the PV module when GTI equals $\mathrm{GTI}_{0},{ }^{\circ} \mathrm{C} ; a$ and $b$ are empirical coefficients depending on the PV module construction and mounting configuration; and WS is the wind speed at a 10 meter height, $\mathrm{m} / \mathrm{s}$.

To derive the $P_{d c}$ from the $P_{a c}$, the terms of Eq. (1) are rearranged to solve for the $P_{d c}$ instead of the $P_{a c}$. This results in Eq. (4):

$$
P_{d c}=P_{s o}+P_{a c} \cdot\left(P_{d c o}-P_{s o}\right) / P_{a c o} .
$$

Deriving the GTI from the $P_{d c}$ requires considering the influence of the GTI on $T$. We substituted Eq. (3) into Eq. (2) and expressed the result as a quadratic equation of the form:

$$
A \cdot \mathrm{GTI}^{2}+B \cdot \mathrm{GTI}+C=0,
$$

where:

$$
\begin{aligned}
& A=\gamma \cdot\left(\Delta T_{c} / \mathrm{GTI}_{0}+e^{a+b \cdot W S}\right), \\
& B=1+\gamma \cdot\left(T_{a}-T_{0}\right), \\
& C=-\mathrm{GTI}_{0} \cdot P_{d c} / P_{d c 0} .
\end{aligned}
$$

The solution for GTI then becomes the standard solution for the quadratic equation. Note that this provides two solutions for the GTI; the one that is physically reasonable is retained (positive and less than $1500 \mathrm{~W} / \mathrm{m}^{2}$ ):

$$
\mathrm{GTI}=\left[-B \pm\left(B^{2}-4 \cdot A \cdot C\right)^{1 / 2}\right] /(2 \cdot A) .
$$

\subsection{Using the GTI-DIRINT model to derive DNI and DHI}


The GTI-DIRINT model was developed using GTI values measured with pyranometers. When using $P_{a c}$ measurements to derive the GTI, it was found useful to incorporate a provision that accounts for the AOI losses due to the increased reflection of solar radiation from the front surface of the PV module when the angle between the solar radiation rays and the normal to the PV module front surface increases. This is accomplished by accounting for AOI losses within the GTI-DIRINT iteration loop for both beam and diffuse irradiances. The various sources of diffuse irradiance (circumsolar diffuse, sky diffuse, horizon diffuse, and ground-reflected diffuse) are considered separately because their range of AOIs and AOI losses differ.

The circumsolar diffuse irradiance is assumed to have the same AOI as the beam irradiance; consequently, they both use the same AOI correction factor, $F_{b}$, which is based on the air-glass model developed by Sjerps-Koomen et al. (1997). The air-glass model resulted from studies that showed that the air-glass interface dominates the transmittance of radiation relative to normal incidence and that other factors are not important. Snell's law is used to determine the angle of refraction in the glass, and Fresnel equations are used to determine the reflection from the glass surface. $F_{b}$ as a function of the AOI is shown in Fig. 1 for a PV module with a glass front-cover with a refractive index, $n$, of 1.526 .

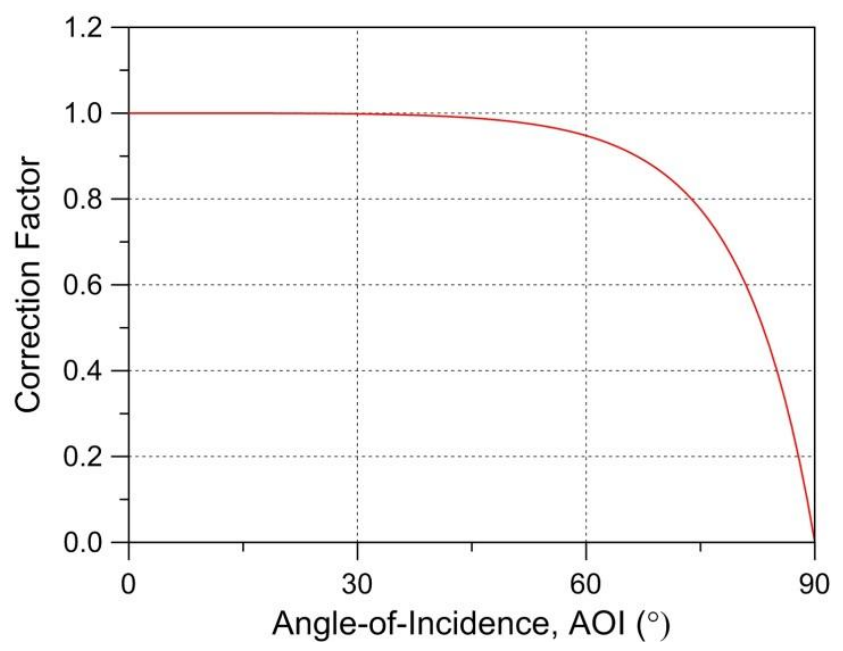

Fig. 1. Angle-of-incidence (AOI) correction factor, $F_{b}$, for beam and circumsolar irradiance for a PV module front-cover material of uncoated glass with a refractive index, $n$, of 1.526 .

For diffuse irradiances other than circumsolar, the PV module receives radiation from a wide range of angles within its $180^{\circ}$ field of view. If the radiation is assumed isotropic, the radiation intensity is the same for all AOIs, but larger AOIs contribute less to the in-plane irradiance because of their cosine, and contribute less to the irradiance reaching the PV cells because of their decreased AOI correction factor, as shown in Fig. 1. Based on the work of Brandemuehl and Beckman (1980), Eq. (10) integrates the effect of the AOI for all angles within the field of view to provide an overall AOI correction factor for the diffuse radiation, $F$ :

$$
F=\frac{\int_{R} F_{b}(A O I) \cdot \cos (A O I) \mathrm{d} \omega}{\int_{R} \cos (A O I) \mathrm{d} \omega}
$$

where $\omega$ is the solid angle of the incident diffuse irradiance and $R$ is the range of $\omega$. An elemental radiation's AOI correction factor is weighted by its contribution to the in-plane irradiance. The range of $\omega, R$, over which the integration is performed, is determined by the type of diffuse radiation being considered (sky diffuse, horizon diffuse, or ground-reflected diffuse) and the PV module tilt angle from the horizontal, $\beta$. Fig. 2 illustrates the results of numerically integrating Eq. (10) for values of $\beta$ from $0^{\circ}$ to $90^{\circ}$ to determine the AOI correction factor for the diffuse sky, $F_{s k y}$; the AOI correction factor the horizon diffuse, $F_{h o r}$; and the AOI correction factor for the ground-reflected diffuse, $F_{\text {grd }}$ (Marion, 2017).

As shown in Fig. 2, $F_{s k y}$ has a small dependency on $\beta$, whereas both $F_{h o r}$ and $F_{g r d}$ are largely dependent on $\beta$ and approach zero as $\beta$ approaches zero. In Fig. 2, the symbols represent the results from the integrations performed at values of $\beta$, and the solid lines are polynomial curve fits of these data. To more readily determine a value of $F_{s k y,} F_{h o r}$, or $F_{\text {grd }}$ for a value of $\beta$, the polynomial curves represented by Eq. (11) may be used as a substitute for performing the integrations:

$$
F=a_{0}+a_{1} \cdot \beta+a_{2} \cdot \beta^{2}+a_{3} \cdot \beta^{3}+a_{4} \cdot \beta^{4}+a_{5} \cdot \beta^{5} .
$$


where values of $a_{\mathrm{n}}$ are the polynomial coefficients and values of $\beta$ are in degrees from 0 to 90 . For a PV module with a glass front-cover, Table 1 provides the polynomial coefficients for $F_{s k y}, F_{h o r}$, and $F_{g r d}$.

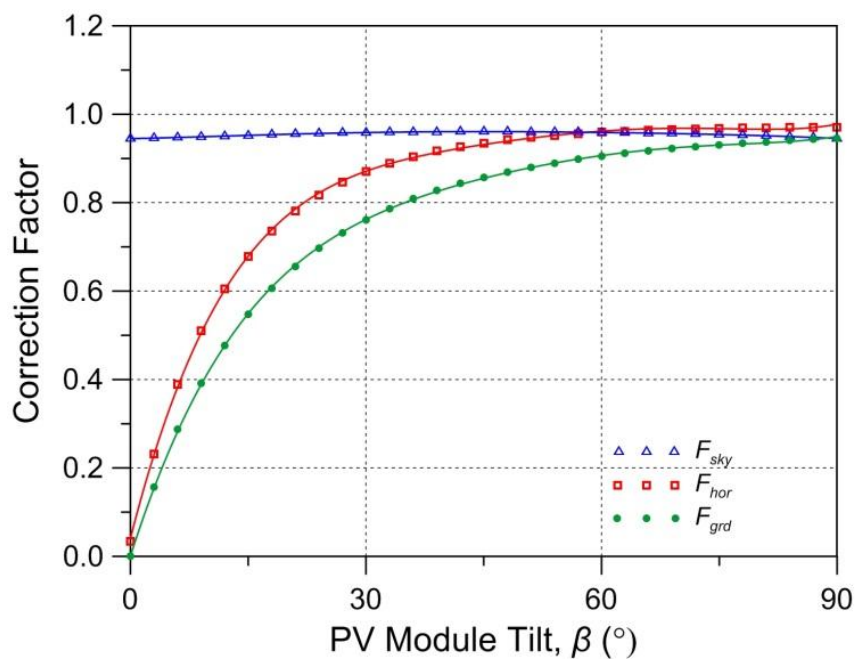

Fig. 2. Angle-of-incidence (AOI) correction factors $F_{s k y}, F_{h o r}$ and $F_{\text {grd }}$ as a function of the PV module tilt angle from horizontal, $\beta$, for a PV module front-cover material of uncoated glass with a refractive index, $n$, of 1.526.

Table 1

Polynomial coefficients for the correction factors $F_{s k y}, F_{h o r}$, and $F_{g r d}$ for a PV module front-cover material of uncoated glass with a refractive index, $n$, of 1.526 .

Correction Polynomial Coefficients

\begin{tabular}{llllrrr} 
Factor & $a_{0}$ & $a_{1}$ & \multicolumn{1}{c}{$a_{2}$} & \multicolumn{1}{l}{$a_{3}$} & \multicolumn{1}{l}{$a_{4}$} & $a_{5}$ \\
\hline$F_{\text {sky }}$ & $9.4487 \mathrm{E}-01$ & $3.4581 \mathrm{E}-04$ & $1.8524 \mathrm{E}-05$ & $-7.0766 \mathrm{E}-07$ & $8.1577 \mathrm{E}-09$ & $-3.3904 \mathrm{E}-11$ \\
$F_{\text {hor }}$ & $4.1215 \mathrm{E}-02$ & $6.9495 \mathrm{E}-02$ & $-2.3414 \mathrm{E}-03$ & $4.1474 \mathrm{E}-05$ & $-3.6908 \mathrm{E}-07$ & $1.2917 \mathrm{E}-09$ \\
$F_{\text {grd }}$ & $6.9258 \mathrm{E}-04$ & $5.5804 \mathrm{E}-02$ & $-1.6406 \mathrm{E}-03$ & $2.7175 \mathrm{E}-05$ & $-2.3399 \mathrm{E}-07$ & $8.0562 \mathrm{E}-10$ \\
\hline
\end{tabular}

Within the GTI-DIRINT model, the iteration loop fine tunes the derivation of the DNI and DHI by comparing the measured GTI, Eq. (9), used for the initial input with a modeled GTI using the derived values of DNI and DHI, and then adjusting the value of the iteration loop GTI, which adjusts the global clearness index, and then iterating values of DNI and DHI until the modeled GTI matches the original measured GTI. The GTI is modeled using the Perez tilted surface transposition model (Perez et al., 1990) and assuming isotropic reflection for the ground-reflected diffuse radiation. The modeled GTI, $\mathrm{GTI}_{m}$, is corrected for AOI losses by applying individual AOI correction factors to the modeled GTI components (beam, sky diffuse, circumsolar diffuse, horizon diffuse, and ground-reflected diffuse) using Eq. (12):

$$
\mathrm{GTI}_{m}=F_{b} \cdot \mathrm{DNI} \cdot c+\mathrm{DHI} \cdot\left[F_{s k y} \cdot\left(1-F_{l}\right) \cdot(1+\cos \beta) / 2+F_{b} \cdot F_{l} \cdot c / d+F_{h o r} \cdot F_{2} \cdot \sin \beta\right]+F_{\text {grd }} \cdot \mathrm{GHI} \cdot \rho \cdot(1-\cos \beta) / 2 \text {. }
$$

where $c=\max (0, \operatorname{cosine}$ of AOI $) ; d=\max (0.087$, cosine of solar zenith angle $) ; F_{l}$ is the Perez model circumsolar anisotropy coefficient; $F_{2}$ is the Perez model horizon/zenith anisotropy coefficient; and $\rho$ is the albedo of the ground. The Perez model coefficients $F_{1}$ and $F_{2}$ are organized as an array of values that are selected for use depending on the solar zenith angle, the sky's clearness, and the sky's brightness. The manner in which this is done is described by Perez et al. (1990).

Fig. 3 is a flow chart of the adaption of the GTI-DIRINT model to use input values of the measured $P_{a c}$ in place of measured values of GTI.

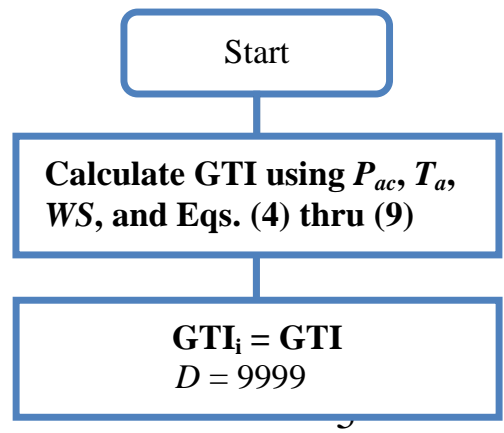


Fig. 3. Flow chart for the adaption of the GTI-DIRINT model to use a measured $P_{a c}$ in place of a measured GTI for model input. Differences from the original model are denoted by a bold font.

\section{Validation data}

We designed the validation experiment to include five identical PV module/Enphase Energy Inc. micro-inverter systems, each with a different tilt and azimuth orientation. The installed PV systems are shown in Fig. 4. Each of the five systems was instrumented to measure the $P_{a c}$ and the GTI. The $P_{a c}$ was measured with a revenue grade meter with an uncertainty of $\pm 0.2 \%$ and the GTI was measured with a secondary standard pyranometer with an uncertainty of $\pm 2 \%$. We used the existing DNI, DHI, WS, and $T_{a}$ measurements from the NREL's Solar Radiation Research Laboratory. The DNI and DHI were used for comparison with 
modeled values, and the WS and $T_{a}$ were used with the $P_{a c}$ to calculate the GTI using Eq. (9). The measurement uncertainty is $\pm 2 \%$ for the DNI, $\pm 4 \%$ for the DHI, $\pm 0.5 \mathrm{~m} / \mathrm{s}$ for the $W S$, and $\pm 0.6^{\circ} \mathrm{C}$ for the $T_{a}$.

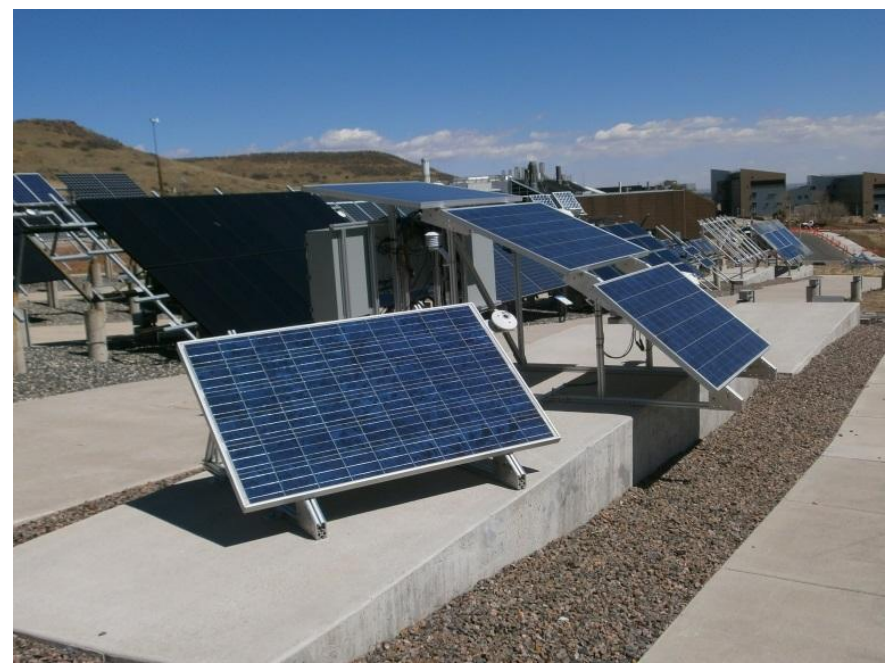

Fig. 4. PV modules with micro-inverters installed at NREL. Three PV modules are south-facing, with tilts of $10^{\circ}, 25^{\circ}$, and $40^{\circ}$ from the horizontal. A fourth PV module is tilted $40^{\circ}$ and faces $30^{\circ}$ west of south. A fifth PV module (not shown) is installed on a nearby two-axis tracker.

The data are 5-minute averages and span the one-year period from April 1, 2014 through March 31, 2015. However, a total of 59 days with snow on the PV modules were excluded. The number of days excluded by month is: April 2014 (4), May 2014 (2), November 2014 (8), December 2014 (12), January 2015 (11), February 2015 (16), and March 2015 (6). For December through February, a significant number of days were excluded, but this did not seriously affect results because the days remaining were a reasonable representation of long-term conditions (Marion, 2015). Hourly digital camera images were used to determine the presence of snow on the PV modules and the ground.

A small amount of data was also not used because they were outside an element's expected range for the NREL site. The expected ranges are: -10 to $1400 \mathrm{~W} / \mathrm{m}^{2}$ for the irradiances; 0 to $225 \mathrm{~W}$ for the $P_{a c}$; the 0 to $40 \mathrm{~m} / \mathrm{s}$ for $W S$; and $-40^{\circ} \mathrm{C}$ to $45^{\circ} \mathrm{C}$ for $T_{a}$.

\section{Implementation and analysis}

Using the characteristic data for the PV systems and the method of Section 2, we derived values of GTI from the $P_{a c}, T_{a}$, and WS data, and then DNI and DHI using the GTI-DIRINT model for the three south-facing PV systems. Each of the three sets of derived DNI and DHI values were then used to model the performance (GTI and $P_{a c}$ ) of each of the five PV systems for the purpose of comparing the differences between the modeled and measured values.

\subsection{PV system characteristic data}

Data specific to the multi-crystalline silicon PV modules and the Enphase Energy Inc. micro-inverters are used with Eqs. (1) through (8). For the PV modules, values of $P_{d c o}$ were measured by NREL's PV Cell and Module Characterization Group. The PV modules had been in service a few years; consequently, updated values were used rather than the nameplate value of $220 \mathrm{~W}$ to account for the $1 \%-2 \%$ degradation that had occurred. For $\gamma$, the PV module manufacturer's value of $-0.0045^{\circ} \mathrm{C}^{-1}$ was used. For modeling $T$, Sandia's coefficients (King et al., 2004) for an open-rack mounted PV module with glass/cell/polymer sheet construction were used: $a=-3.56, b=-0.075$, and $\Delta T_{c}=3^{\circ} \mathrm{C}$.

For the Enphase M215 micro-inverter, characteristic data were determined from information from the California Energy Commission inverter test summary (2016), with $P_{a c o}=215.0 \mathrm{~W}, P_{d c o}=224.4 \mathrm{~W}$, and $P_{s o}=0.32 \mathrm{~W}$.

\subsection{Deriving the DNI and DHI}

Using the method described in Section 2, data sets of DNI and DHI, with a resolution of 5 minutes, were determined from the $P_{a c}$ data for each of the three PV systems and the $T_{a}$ and WS data. Data were used for times when the sun was above the horizon, 
with the sun position calculated for the midpoint of the 5-minute data interval. For modeling values of GTI within the GTIDIRINT iteration loop, an albedo of 0.2 was assumed, unless there was snow on the ground, in which case an albedo of 0.6 was used.

\subsection{Modeling PV system performance}

To judge the suitability for predicting PV system performance, each of the three derived DNI and DHI data sets was used to model the performance of each of the five PV systems. The GTI and $P_{a c}$ were modeled using the Perez tilted surface transposition model and Eqs. (1), (2), (3), and (12) and then compared with the measured values of GTI and $P_{a c}$. Like Section 4.2, data were used for times when the sun was above the horizon, with the sun position calculated for the midpoint of the 5-minute data interval. For contrasting with using conventional sources of DNI and DHI for modeling the GTI and $P_{a c}$, similar PV performance modeling was performed using: 1) measured values of DNI and DHI, and 2) modeled values of DNI and DHI derived from GHI using the DIRINT model.

\subsection{Analysis}

The performance of the modeling was evaluated using the mean bias deviation (MBD) and the root-mean-square deviation (RMSD) statistics, with the results expressed as a percent of the mean of the measured values. The deviation is the measured value subtracted from the modeled value. For the MBD, a positive value indicates that the model overestimates on average.

$$
\begin{aligned}
& \operatorname{MBD}=100 \cdot\left[(1 / m) \cdot \sum\left(y_{i}-x_{i}\right)\right] \div\left[(1 / m) \cdot \sum x_{i}\right], \\
& \operatorname{RMSD}=100 \cdot\left[(1 / m) \cdot \sum\left(y_{i}-x_{i}\right)^{2}\right]^{1 / 2} \div\left[(1 / m) \cdot \sum x_{i}\right] .
\end{aligned}
$$

where $y_{i}$ is the $i$ th modeled value; $x_{i}$ is the $i$ th measured value; and $m$ is the number of measured or modeled values.

The means of the measured irradiance values are: DNI $=476 \mathrm{~W} / \mathrm{m}^{2} ; \mathrm{DHI}=147 \mathrm{~W} / \mathrm{m}^{2} ; \mathrm{GHI}=423 \mathrm{~W} / \mathrm{m}^{2} ; \mathrm{GTI}(10,180)=457$ $\mathrm{W} / \mathrm{m}^{2} ; \operatorname{GTI}(25,180)=483 \mathrm{~W} / \mathrm{m}^{2} ; \operatorname{GTI}(40,180)=489 \mathrm{~W} / \mathrm{m}^{2} ; \operatorname{GTI}(40,210)=450 \mathrm{~W} / \mathrm{m}^{2} ;$ and $\operatorname{GTI}(2 X \operatorname{Trk})=652 \mathrm{~W} / \mathrm{m}^{2} ;$ where the GTI(Tilt, Orientation) notation of Vignola et al. (2012) is used where Tilt is in degrees from horizontal and Orientation is the azimuth in degrees measured eastward from true north. We designated the two-axis tracking orientation as GTI (2X Trk).

Using the same notation, the means of the ac power values measured by NREL are: $P_{a c}(10,180)=87.7 \mathrm{~W} ; P_{a c}(25,180)=92.2$ $\mathrm{W} ; P_{a c}(40,180)=91.7 \mathrm{~W} ; P_{a c}(40,210)=83.9 \mathrm{~W} ;$ and $P_{a c}(2 \mathrm{X}$ Trk $)=122.9 \mathrm{~W}$.

\section{Results}

This section compares the modeled and measured values of DNI, DHI, GHI, GTI, and $P_{a c}$ using MBD and RMSD statistics and illustrates the benefit of the AOI correction and the method's minimization of the influence of variations in the solar spectrum when modeling the $P_{a c}$.

\subsection{Statistics for deriving the GTI from the $P_{a c}$ and modeling DNI, DHI, and GHI}

Using the measured $P_{a c}$ values, their GTIs were derived using Eqs. (4) through (9), and then values of DNI and DHI were derived from the GTIs using the GTI-DIRINT model with incorporation of Eq. (12). The MBD and RMSD results for deriving the GTI from the $P_{a c}$ values for each of the three PV systems are shown in Table 2. The GTIs derived from the measured $P_{a c}$ are not corrected for AOI losses ( 3\%); consequently, the negative MBDs in Table 2 are reasonable and expected. AOI losses are accommodated within the GTI-DIRINT model.

Table 2

Mean bias deviation (MBD) and root-mean-square deviation (RMSD) for deriving the GTI from the measured $P_{a c}$

\begin{tabular}{lrrr} 
GTI & $\begin{array}{r}\text { Mean } \\
\left(\mathrm{W} / \mathrm{m}^{2}\right)\end{array}$ & $\begin{array}{r}\text { MBD } \\
(\%)\end{array}$ & $\begin{array}{r}\text { RMSD } \\
(\%)\end{array}$ \\
\hline $\operatorname{GTI}(10,180)$ & 457 & -2.7 & 5.3 \\
$\operatorname{GTI}(25,180)$ & 483 & -2.2 & 4.3 \\
$\operatorname{GTI}(40,180)$ & 489 & -3.8 & 5.6 \\
\hline
\end{tabular}


The MDB and RMSD results for modeling the DNI and DHI are shown in Table 3. Also shown in Table 3 are the results for the conventional approach of using the DIRINT model to derive DNI and DHI from the GHI. Results for calculating the GHI from derived values of DNI and DHI are also provided for the application of the GTI-DIRINT model (not included when using the DIRINT model because the GHI is a model input).

Compared to DIRINT, the applications using GTI-DIRINT had similar MBDs. The RMSD for DNI was increased, but was still reasonable. The MBDs for the calculated GHI were within the $\pm 2 \%$ uncertainty of the measurement.

Table 3

Mean bias deviation (MBD) and root-mean-square deviation (RMSD) for DIRINT and GTI-DIRINT modeled values of DNI, DHI, and GHI when using the measured GHI with DIRINT and the measured $P_{a c}$ with GTI-DIRINT for the various PV module tilt and azimuth orientations.

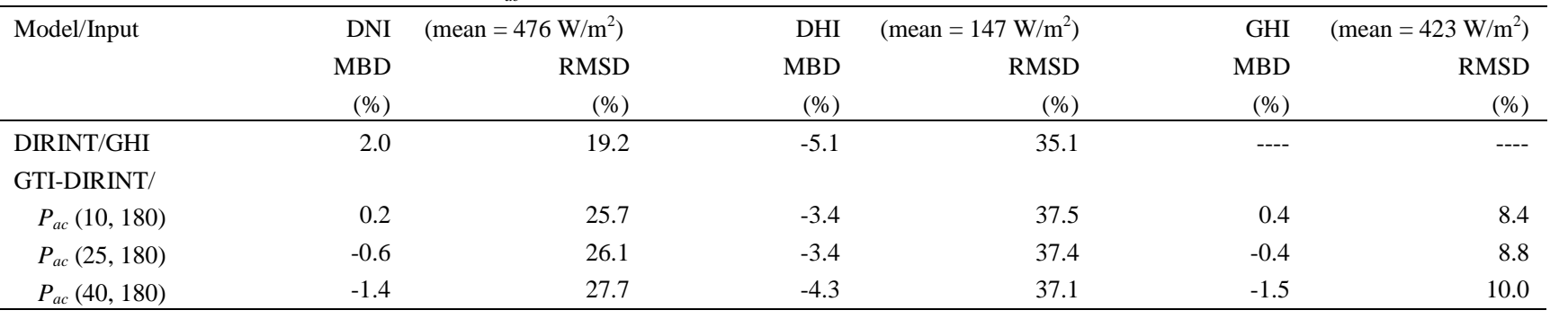

\subsection{Statistics for modeling GTI}

The DNI and DHI values derived as described in Section 5.1 were used with the Perez tilted surface model to model the GTIs for the different PV module orientations. Because AOI losses are addressed within the GTI-DIRINT model, using the derived DNI and DHI to model the GTI provides values closer to those measured with a pyranometer than by deriving the GTI directly from the measured $P_{a c}$ (see Table 2).

The MDB and RMSD results for modeling the GTI from the DNI and DHI are shown in Table 4. For comparison, both measured, DIRINT, and GTI-DIRINT derived values of DNI and DHI were used to model the GTIs for the different PV module orientations. When using the measured values of DNI and DHI to model the GTIs, the MBDs were within $\pm 1 \%$. MBDs were only slightly greater, within $\pm 1.5 \%$, for either the DIRINT model when using measured values of GHI for model input or when using the DNI and DHI values derived from the $P_{a c}$ values and the GTI-DIRINT model for the various PV module orientations.

The method based on $P_{a c}$ had the largest RMSDs for the GTI(2X Trk), presumably because this orientation has a large DNI component and the RMSD for DNI (see Table 3) was larger for this method. For other orientations, the RMSD was less than the other methods, but this is a consequence of the $P_{a c}$ and GTI measurements being co-located, and the DNI, DHI, and GHI being measured approximately 330 meters to the north. Cloud movement can influence the relative measurements at two locations, particularly for shorter averaging intervals, and account for some of the differences in RMSDs. When we increased the data averaging interval from five minutes to one hour, the 330 meter distance between the measurement locations was no longer important and the RMSDs for all methods were essentially the same.

Table 4

Mean bias deviation (MBD) and root-mean-square deviation (RMSD) for modeling the GTI for the different PV module orientations when using the measured DNI and DHI; the DIRINT modeled DNI and DHI derived from the measured GHI; and the GTI-DIRINT modeled values of DNI and DHI derived from the measured $P_{a c}$ for the various PV module tilt and azimuth orientations.

\begin{tabular}{|c|c|c|c|c|c|c|c|c|c|c|}
\hline \multirow[t]{2}{*}{$\begin{array}{l}\text { Source for } \\
\text { DNI and DHI }\end{array}$} & \multicolumn{2}{|c|}{$\begin{array}{c}\text { GTI }(10,180) \\
\left(\text { mean }=457 \mathrm{~W} / \mathrm{m}^{2}\right)\end{array}$} & \multicolumn{2}{|c|}{$\begin{array}{c}\operatorname{GTI}(25,180) \\
\left(\text { mean }=483 \mathrm{~W} / \mathrm{m}^{2}\right)\end{array}$} & \multicolumn{2}{|c|}{$\begin{array}{c}\text { GTI }(40,180) \\
\left(\text { mean }=489 \mathrm{~W} / \mathrm{m}^{2}\right)\end{array}$} & \multicolumn{2}{|c|}{$\begin{array}{c}\text { GTI }(40,210) \\
\left(\text { mean }=450 \mathrm{~W} / \mathrm{m}^{2}\right)\end{array}$} & \multicolumn{2}{|c|}{$\begin{array}{c}\text { GTI }(2 X \text { Trk }) \\
\left(\text { mean }=652 \mathrm{~W} / \mathrm{m}^{2}\right)\end{array}$} \\
\hline & $\begin{array}{r}\text { MBD } \\
(\%)\end{array}$ & $\begin{array}{r}\text { RMSD } \\
(\%)\end{array}$ & $\begin{array}{r}\text { MBD } \\
(\%)\end{array}$ & $\begin{array}{r}\text { RMSD } \\
(\%)\end{array}$ & $\begin{array}{r}\text { MBD } \\
(\%)\end{array}$ & $\begin{array}{r}\text { RMSD } \\
(\%)\end{array}$ & $\begin{array}{r}\text { MBD } \\
(\%)\end{array}$ & $\begin{array}{r}\text { RMSD } \\
(\%)\end{array}$ & $\begin{array}{r}\mathrm{MBD} \\
(\%)\end{array}$ & $\begin{array}{r}\text { RMSD } \\
(\%)\end{array}$ \\
\hline Measured & -0.1 & 7.4 & 0.5 & 7.6 & -0.1 & 7.9 & 0.1 & 8.4 & 0.9 & 7.5 \\
\hline DIRINT/GHI & 0.0 & 7.4 & 0.7 & 8.0 & 0.2 & 8.7 & 0.2 & 9.5 & 1.4 & 10.6 \\
\hline \multicolumn{11}{|l|}{ GTI-DIRINT/ } \\
\hline$P_{a c}(10,180)$ & 0.6 & 4.3 & 1.3 & 4.7 & 0.8 & 5.5 & 1.0 & 6.2 & 0.5 & 13.9 \\
\hline$P_{a c}(25,180)$ & -0.3 & 4.5 & 0.4 & 3.7 & -0.1 & 4.0 & 0.1 & 5.2 & 0.0 & 14.7 \\
\hline$P_{a c}(40,180)$ & -1.5 & 6.1 & -0.8 & 4.5 & -1.3 & 4.2 & -1.0 & 5.6 & -0.9 & 16.7 \\
\hline
\end{tabular}

Fig. 5 is a scatterplot of the modeled versus measured GTI(40,210) when using DNI and DHI values derived from the measured $P_{a c}(25,180)$ for input to the Perez tilted surface model. The diagonal in Fig. 5 has a slope of one to facilitate comparing modeled 
and measured values. Data points above the line indicate model overestimates and data points below the line indicate model underestimates. Overall, agreement between modeled and measured values is quite good.

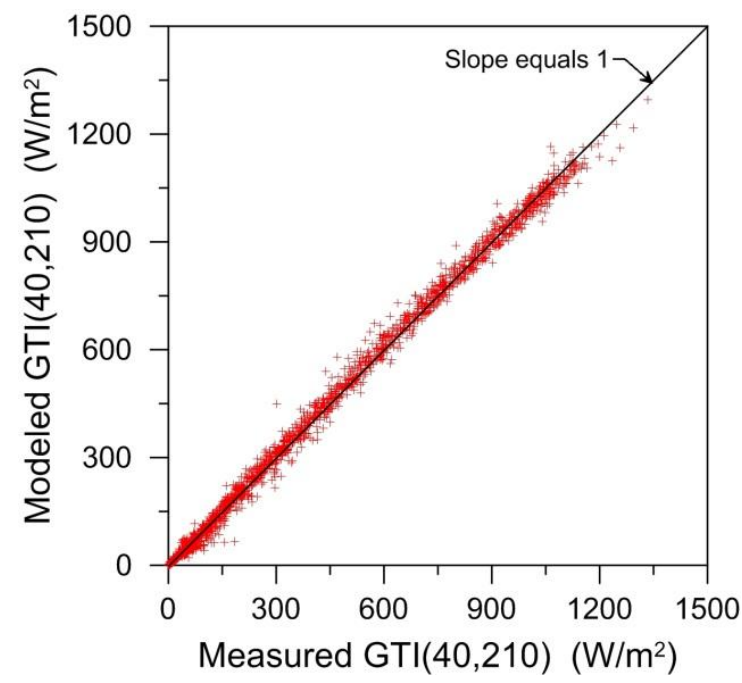

Fig. 5. Modeled versus measured GTI $(40,210)$ using model input values of DNI and DHI derived from the measured $P_{a c}(25,180)$.

\subsection{Statistics for modeling $P_{a c}$}

The GTI values described in Section 5.2 were used with Eqs. (1), (2), (3), and (12) to model the $P_{a c}$ for comparison with the measured $P_{a c}$. The MDB and RMSD results are shown in Table 5. When using the measured values of DNI and DHI as the source of data for modeling the GTIs, the MBDs were within $\pm 1.9 \%$ for modeling the $P_{a c}$. MBDs were slightly greater, within $\pm 2.2 \%$, when using the DIRINT modeled values of the DNI and DHI. When DNI and DHI values were derived from the measured $P_{a c}$ values for the various PV module orientations, MBDs were within $\pm 2.8 \%$ for modeling the $P_{a c}$.

When the source of the DNI and DHI is the measured $P_{a c}$ for the same orientation as modeled, the MDBs and RMSDs in Table 5 are near zero, indicating that the measured $P_{a c}$ is able to predict itself and the method is working properly. When used to model the $P_{a c}$ for other orientations, the MBDs and RMSDs increase, with some values being larger than when modeling the GTI. This may be a consequence of the $\pm 3 \%$ uncertainty of the PV module rating, $P_{d c}$. The method uses a $P_{d c 0}$ once when deriving the DNI and DHI for modeling the GTI, and again for modeling the $P_{a c}$.

Table 5

Mean bias deviation (MBD) and root-mean-square deviation (RMSD) for modeling the $P_{a c}$ for the different PV module orientations when using the measured DNI and DHI; the DIRINT modeled DNI and DHI derived from the measured GHI; and the GTI-DIRINT modeled values of DNI and DHI derived from the measured $P_{a c}$ for the various PV module tilt and azimuth orientations.

\begin{tabular}{|c|c|c|c|c|c|c|c|c|c|c|}
\hline \multirow{3}{*}{$\begin{array}{l}\text { Source for } \\
\text { DNI and DHI }\end{array}$} & \multicolumn{2}{|c|}{$P_{a c}(10,180)$} & \multicolumn{2}{|c|}{$P_{a c}(25,180)$} & \multicolumn{2}{|c|}{$P_{a c}(40,180)$} & \multicolumn{2}{|c|}{$P_{a c}(40,210)$} & \multicolumn{2}{|c|}{$P_{a c}(2 \mathrm{X}$ Trk $)$} \\
\hline & MBD & RMSD & MBD & RMSD & MBD & RMSD & MBD & RMSD & MBD & RMSD \\
\hline & $(\%)$ & $(\%)$ & $(\%)$ & $(\%)$ & $(\%)$ & $(\%)$ & $(\%)$ & $(\%)$ & $(\%)$ & $(\%)$ \\
\hline Measured & -0.8 & 7.8 & -0.1 & 7.6 & 0.9 & 8.1 & 1.9 & 9.0 & 1.8 & 7.8 \\
\hline DIRINT/GHI & -0.7 & 7.8 & 0.1 & 7.9 & 1.2 & 8.9 & 2.0 & 10.0 & 2.2 & 11.0 \\
\hline \multicolumn{11}{|l|}{ GTI-DIRINT/ } \\
\hline$P_{a c}(10,180)$ & -0.1 & 0.1 & 0.7 & 3.2 & 1.8 & 4.9 & 2.8 & 6.4 & 1.3 & 15.1 \\
\hline$P_{a c}(25,180)$ & -0.9 & 3.4 & -0.1 & 0.2 & 1.0 & 2.2 & 2.0 & 4.9 & 0.9 & 15.7 \\
\hline$P_{a c}(40,180)$ & -2.0 & 5.4 & -1.2 & 2.4 & -0.1 & 0.3 & 0.9 & 4.6 & 0.1 & 17.5 \\
\hline
\end{tabular}

Fig. 6 is a scatterplot of the modeled versus measured $P_{a c}(40,210)$ when using DNI and DHI values derived from the measured $P_{a c}(25,180)$. Compared to the scatterplot for the modeled GTI in Fig. 5, the degree of scatter is similar or less, but the modeled values are slightly overestimated. 


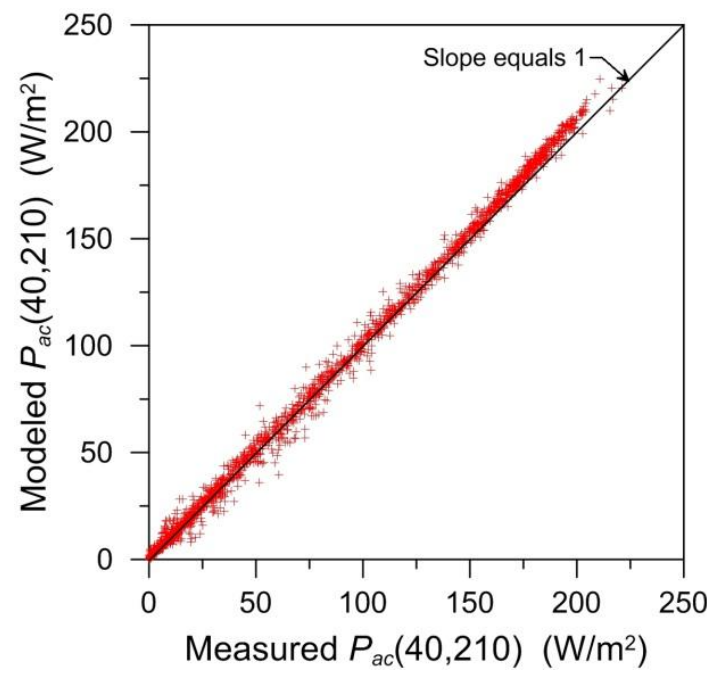

Fig. 6. Modeled versus measured $P_{a c}(40,210)$ using model input values of DNI and DHI derived from the measured $P_{a c}(25,180)$.

\subsection{Benefit of the AOI correction}

The calculated annual AOI losses range from $0.8 \%$ for $P_{a c}\left(2 \mathrm{X}\right.$ Trk) to $3.5 \%$ for $P_{a c}(10,180)$. To better understand the value of AOI corrections within the method, it was also implemented without the use of AOI corrections. Without the use of the AOI corrections, the method deduces less solar radiation present. The MBD for DHI is not affected significantly, but the MBD for DNI is shifted about $8 \%$ more negative. When the DNI and DHI values are then used for modeling GTIs, the GTIs are underestimated - and more so for orientations with a larger DNI component, such as GTI(2X Trk). The impact on modeling the $P_{a c}$ is less, but also depends on orientation. As discussed previously, when the source of the DNI and DHI is the measured $P_{a c}$ for the same orientation as modeled, the MDBs and RMSDs are near zero for modeling the $P_{a c}$ (if the same PV models are used). For other orientations, the MDBs and RMSDs are larger, especially if the AOI correction is not included and the modeled orientation is substantially different. Fig. 7 illustrates the advantage of using AOI corrections.

Without using AOI corrections, the MBD for $P_{a c}$ was positive with respect to the MBD for the GTI. For $P_{a c}(40,210)$, the MBD is $5 \%$ greater than for the MBD for GTI $(40,210)$. This is a consequence of the $+2 \%$ MBD of the method for this orientation-the MBD for $P_{a c}(40,210)$ with AOI correction-and a $+3 \%$ MBD due to not accounting for a $3 \%$ AOI loss.

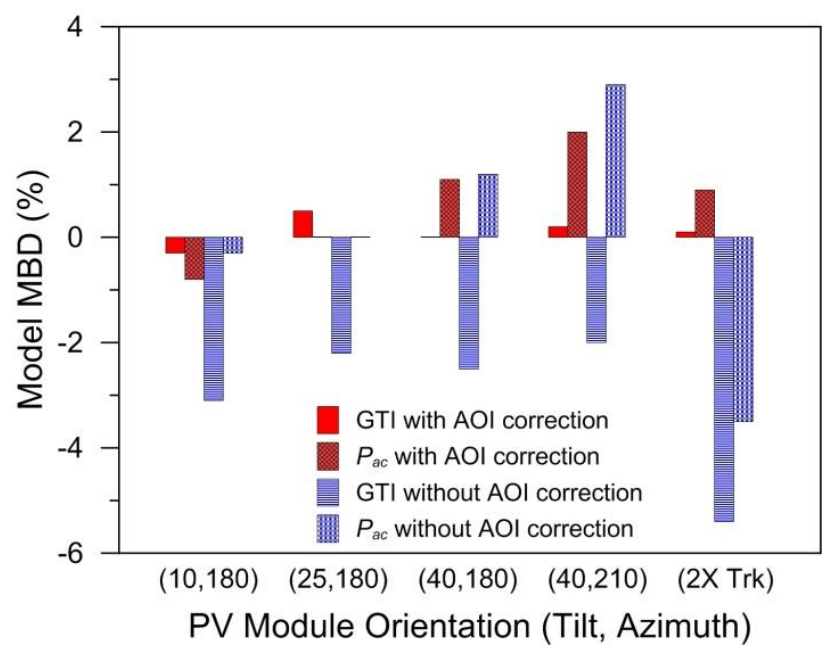

Fig. 7. Mean bias deviation (MBD) for the modeled GTI and $P_{a c}$ when using the DNI and DHI values derived from the measured $P_{a c}(25,180)$. For the modeled $P_{a c}(25,180)$, the MBD is zero for with or without AOI corrections. For other orientations, the MBD for $P_{a c}$ was better when using AOI corrections if the orientation was substantially different $\left(P_{a c}(40,210)\right.$ and $P_{a c}(2 \mathrm{X}$ Trk $\left.)\right)$. Using AOI corrections always gave the best result for the MBD for GTI. 


\subsection{Comparison with a power-projection method}

As discussed in the introduction, our method shares similarities with the power projection method of Killinger et al. (2016). To compare results for the two methods, we applied the Killinger method to the NREL PV performance data. The primary difference of the two methods is the equation for deriving the GTI from the $P_{a c}$. From Killinger et al. (2016) and Killinger et al. (2017), the specific power may be represented by Eq. (13):

$$
P_{a c} / P_{a c 0}=c_{6} \cdot\left(c_{0}+c_{1} \cdot \mathrm{GTI}+c_{2} \cdot T_{a}+c_{3} \cdot \mathrm{GTI} \cdot T_{a}+c_{4} \cdot \mathrm{GTI}^{2}+c_{5} \cdot T_{a}^{2}\right),
$$

where $P_{a c 0}$ is the ac power at STC, W; for crystalline silicon PV modules, $c_{0}=-0.023476 ; c_{1}=0.001138 ; c_{2}=-0.000196 ; c_{3}=-$ $0.000004 ; c_{4}=0.0 ; c_{5}=0.000004$; and to account for losses due to dirt, degradation, etc., $c_{6}=0.875$. The $c_{n}$ coefficients account the PV module's and inverter's losses and variation in efficiency over the range of conditions experienced.

The terms of Eq. (13) may be rearranged to solve for the GTI, with the $c_{4} \cdot \mathrm{GTI}^{2}$ term not needed because $c_{4}$ equals zero. This results in Eq. (14):

$$
\mathrm{GTI}=\left[P_{a c} /\left(c_{6} \cdot P_{a c 0}\right)-c_{1} \cdot \mathrm{GTI}-c_{2} \cdot T_{a}-c_{5} \cdot T_{a}^{2}\right] /\left(c_{1}+c_{3} \cdot T_{a}\right) .
$$

For each of the three south-facing PV systems, the Killinger method was implemented by using Eq. (14) in place of Eq. (9) to derive the GTI from the $P_{a c}$; using the GTI-DIRINT model without the AOI provision to derive the DNI and DHI from the GTI; using the Perez tilted surface model and the derived DNI and DHI to model the GTI for each of the five PV systems; and using Eq. (13) and the modeled GTI to model the $P_{a c}$ for each of the five PV systems. The error statistics for modeling $P_{a c}$ are provided in Table 6. Compared to the NREL method, the MBD range is greater: $-2.5 \%$ to $5.2 \%$ versus $-2.0 \%$ to $2.8 \%$. The RMSD values are also greater. The NREL method results are better because it accounts for the effect of WS on $T$ and for AOI losses.

Table 6

Mean bias deviation (MBD) and root-mean-square deviation (RMSD) for modeling the $P_{a c}$ for the different PV module orientations when using the Killinger

\begin{tabular}{|c|c|c|c|c|c|c|c|c|c|c|}
\hline \multirow{2}{*}{$\begin{array}{l}\text { Source for } \\
\text { DNI and DHI }\end{array}$} & \multicolumn{2}{|c|}{$P_{a c}(10,180)$} & \multicolumn{2}{|c|}{$P_{a c}(25,180)$} & \multicolumn{2}{|c|}{$P_{a c}(40,180)$} & \multicolumn{2}{|c|}{$P_{a c}(40,210)$} & \multicolumn{2}{|c|}{$P_{a c}(2 \mathrm{X}$ Trk $)$} \\
\hline & $\begin{array}{r}\text { MBD } \\
(\%)\end{array}$ & $\begin{array}{r}\text { RMSD } \\
(\%)\end{array}$ & $\begin{array}{r}\text { MBD } \\
(\%)\end{array}$ & $\begin{array}{r}\text { RMSD } \\
(\%)\end{array}$ & $\begin{array}{r}\text { MBD } \\
(\%)\end{array}$ & $\begin{array}{r}\text { RMSD } \\
(\%)\end{array}$ & $\begin{array}{r}\text { MBD } \\
(\%)\end{array}$ & $\begin{array}{r}\text { RMSD } \\
(\%)\end{array}$ & $\begin{array}{r}\text { MBD } \\
(\%)\end{array}$ & $\begin{array}{r}\text { RMSD } \\
(\%)\end{array}$ \\
\hline \multicolumn{11}{|l|}{ GTI-DIRINT/ } \\
\hline$P_{a c}(10,180)$ & -0.1 & 0.6 & 1.6 & 4.3 & 3.1 & 6.9 & 3.6 & 8.6 & 5.2 & 14.4 \\
\hline$P_{a c}(25,180)$ & -1.2 & 4.1 & 0.5 & 1.1 & 1.9 & 3.6 & 2.4 & 6.5 & 3.9 & 14.8 \\
\hline$P_{a c}(40,180)$ & -2.5 & 6.4 & -0.9 & 2.8 & 0.5 & 1.4 & 1.1 & 5.8 & 2.5 & 16.8 \\
\hline
\end{tabular}
method.

\section{Summary and conclusions}

A method was presented and validated for using PV performance data for south-facing PV systems as a means to provide lowcost solar resource data for modeling the performance of nearby PV systems with arbitrary PV module orientations. The method uses conventional PV model equations, but rearranged, to determine the $P_{d c}$ from the measured $P_{a c}$, and the GTI from the $P_{d c}$ after accounting for effects of the air temperature and wind speed on $T$. The solar resource, values of DNI and DHI, are then derived from the GTI values using the GTI-DIRINT model with a modification to correct for AOI effects. The correction for AOI effects is an important feature of the method to prevent underestimating the solar resource and for modeling the performance of PV systems with more dissimilar PV module orientations.

For the three south-facing PV module/micro-inverter systems, the values of DNI derived from their measured 5-minute averages of $P_{a c}$ had similar annual MBDs to those derived from measured values of GHI using the DIRINT model $(<2 \%)$, but the RMSDs were larger-28\% versus 19\%. For DHI, the MBDs and RMSDs were essentially the same as for the DIRINT model.

When using the DNI and DHI values derived from the measured $P_{a c}$ values to model the annual GTI for the five different PV module orientations, the MBDs were within $\pm 1.5 \%$, which is the same as was determined when using measured values of GHI and the DIRINT model to derive the DNI and DHI. The RMSD of $17 \%$ for the GTI(2X Trk) was the largest because of its increased DNI component. For the same orientation, the RMSD was $11 \%$ when using measured values of GHI and the DIRINT model. 
The modeled GTI values were used with the PV performance equations to model the annual $P_{a c}$ for comparison with the measured values of $P_{a c}$. When using the measured values of DNI and DHI as the source of data for modeling the GTIs, the MBDs for modeling the $P_{a c}$ were within $\pm 1.9 \%$. MBDs were slightly greater, within $\pm 2.2 \%$, when using the DIRINT modeled values of DNI and DHI. When DNI and DHI values were derived from the measured $P_{a c}$ values for the various PV module orientations, MBDs were within $\pm 2.8 \%$ for modeling the $P_{a c}$. This was shown to be an improvement over Killinger's power projection method because it accounts for the effect of $W S$ on $T$ and for AOI losses.

The method's MBDs for modeling the $P_{a c}$ was only slight greater than when using the DIRINT model and measured values of GHI. Compared to today's large number of installed PV module/micro-inverter systems, the availability of measured GHI is extremely low. Consequently, the method exhibits great potential for providing useful ground-based solar resource data for predicting the performance of PV systems.

For those interested in implementing the method, source code will be available. The U.S. Department of Energy requires that scientific and technical information, including scientific and technical computer software, be made broadly available to the public.

\section{Future work}

The next phase of work will apply the method to $20 \mathrm{PV}$ module/micro-inverter systems in each of five metropolitan areas: Phoenix, AZ; New Orleans, LA; Denver, CO; Seattle, WA, and Minneapolis/St. Paul, MN. This number of PV installations affords the opportunity to evaluate the method's tolerance for non-south orientations of the PV module, the effect of the distance between PV systems, and the use of regional meteorological data for $W S$ and $T_{a}$. It will be representative of a commercial implementation of the method: nameplate values will be used for PV module and inverter characteristics and the micro-inverter $P_{a c}$ values will be those measured and archived by Enphase Energy Inc. under their Enlighten ${ }^{\circledR}$ program. The Enphase Energy Inc. $P_{a c}$ values have an uncertainty of $\pm 2.5 \%$.

The results for the method will be compared with the results when using satellite-based GHI values to model the PV performance, which is a logical alternative. Satellite-based solar resource data provide good spatial resolution. The typical uncertainty of the satellite-based GHI is about $\pm 5 \%$ (Richter et al., 2015).

Work to account for the impact of variations in solar spectrum on the output of the PV module may also benefit the method. Similar to the use of a PV reference cell, the use of PV performance data to derive the solar resource may mitigate the impact of variations in solar spectrum, but the spectral irradiance distribution of the GTI also depends of the PV module orientation due to differences in the direct and diffuse irradiance contributions. The spectral distribution of the direct and diffuse irradiance is quite different, with the direct irradiance shifted toward the longer wavelengths. Typically, PV system modeling software does not correct the performance of crystalline silicon PV modules for spectral effects because the uncertainty of the correction, for air mass functions, is greater than the uncertainty of the effect (Osterwald et al., 2014). However, the recent work of Lee and Panchula (2016) indicates that by also incorporating the effects of precipitable water vapor, a useful spectral correction may be performed.

\section{Acknowledgement}

This work was supported by the U.S. Department of Energy under Contract No. DE-AC36-08-GO28308 with the National Renewable Energy Laboratory (NREL). Funding provided by U.S. DOE Office of Energy Efficiency and Renewable Energy Solar Energy Technologies Program. The author is thankful for the efforts of Bill Sekulic, Jose Rodriguez, and Greg Perrin at NREL, who performed the irradiance and PV performance measurements.

The U.S. Government retains and the publisher, by accepting the article for publication, acknowledges that the U.S. Government retains a nonexclusive, paid-up, irrevocable, worldwide license to publish or reproduce the published form of this work, or allow others to do so, for U.S. Government purposes.

\section{References}

California Energy Commission, http://www.gosolarcalifornia.ca.gov/equipment/inverter_tests/summaries/Enphase\%20M215-602LL-S2x\%20(240V).pdf, accessed 1/6/2016.

Brandemuehl, M.J., Beckman, W.A., 1980. Transmission of diffuse light through CPC and flat plate collector glazings, Solar Energy 24, 511-513.

da Costa, W., Fardin, J., Neto, L., Simonetti, D., 2014. Estimation of irradiance and temperature using photovoltaic modules, Solar Energy 110, 132-138.

Engerer, N., Mills, F., 2014. KPV: A clear-sky index for photovoltaics, Solar Energy 105, 679-693.

Engerer, N., Xu, Y., 2015. A simple model for estimating the diffuse fraction of solar irradiance from photovoltaic array power output, in $21^{\text {st }}$ International Congress on Modelling and Simulation. 
Evans, D.L., Florschuetz, L.W., 1977. Cost studies on terrestrial photovoltaic power systems with sunlight concentration. Solar Energy 19, 255-262.

Gostein, M., Stueve, B., Passow, K., Marion, B., 2016. Evaluating a model to estimate GHI, DNI, and DHI from POA irradiance, in $32^{\text {nd }}$ EUPVSEC.

Killinger, S., Braam, F., Muller, B., Wille-Haussmann, B., McKenna, R., 2016. Projection of power generation between differently-oriented PV systems, Solar Energy 136, 153-165.

Killinger, S., Engerer, N., Muller, B., 2017. QCPV: A quality control algorithm for distributed photovoltaic array power output, Solar Energy 143, 120-131.

King, D., Boyson, W., Kratochvil, J., 2004. Photovoltaic Array Performance Model, Sandia National Laboratories, Albuquerque, NM.

King, D., Gonzalez, S., Galbraith, G., Boyson, W., 2007. Performance Model for Grid-Connected Photovoltaic Inverters, Sandia National Laboratories, Albuquerque, NM.

Lee, M., Panchula, A., 2016. Spectral correction for photovoltaic module performance based on air mass and precipitable water, in $43^{\text {rd }}$ IEEE PVSC.

Lonij, V., Jayadevan, V., Brooks, A., Rodriguez, J., Koch, K., Leuthold, M., Cronin, A., 2012. Forecasts of PV power output using power measurements of 80 residential PV installs, in $38^{\text {th }}$ IEEE PVSC.

Marion, B., 2015. A model for deriving the direct normal and diffuse horizontal irradiance from the global tilted irradiance, Solar Energy 122, 1037-1046.

Marion, B., 2017. Numerical method for angle-of-incidence correction factors for diffuse radiation incident photovoltaic modules, Solar Energy, in press.

Osterwald, C., Emery, K., Muller, M., 2014. Photovoltaic module calibration value versus optical air mass: the air mass function, Prog. Photovolt: Res. Appl. 22, 560-573.

Perez, R., Ineichen, P., Seals, R., Michalsky, J., 1990. Modeling daylight availability and irradiance components from direct and global irradiance, Solar Energy 44, 271-289.

Perez, R., Ineichen, P., Maxwell, E., Seals, R., Zelenka, A., 1992. Dynamic global-to-direct irradiance conversion models, in ASHRAE Transactions-Research Series, 354-369.

Richter, M., De Brabandere, K., Kalisch, J., Schmidt, T., Lorenz, E., 2015. Best Practice Guide On Uncertainty in PV Modelling, $3 \mathrm{E}$ - University of Oldenburg, Brussels, Belgium.

Sjerps-Koomen, E.A., Alsema, E.A., Turkenburg, W.C., 1997. A simple model for PV module reflection losses under field conditions, Solar Energy 57, 421-432.

Vignola, F., Michalsky, J., Stoffel, T., 2012. Solar and infrared radiation measurements, CRC Press, Boca Raton.

Yang, D., Dong, S., Nobre, A., Khoo, Y., Jirutitijaroen, P., Walsh, W., 2013. Evaluation of transposition and decomposition models for converting global solar irradiance from tilted surface to horizontal in tropical regions, Solar Energy 97, 369-387.

Yang, D., Ye, Z., Nobre, A., Du, H., Walsh, W., Lim, L., Reindl, T., 2014. Bidirectional irradiance transposition based on the Perez model, Solar Energy 110, 768-780. 